\title{
Improvement of Infraorbital Rim contour Using Medpor
}

\author{
So Min Hwang, \\ Seong Hyuk Park, \\ Jong Seo Lee, \\ Hyung Do Kim, \\ Min Kyu Hwang, \\ Min Wook Kim \\ Aesthetic, Plastic and Reconstructive Surgery \\ Center, Good Moonhwa Hospital, Busan, \\ Korea
}

No potential conflict of interest relevant to this article was reported.

\begin{abstract}
Background: Asymmetry of the infraorbital rim can be caused by trauma, congenital or acquired disease, or insufficient reduction during a previous operation. Such asymmetry needs to be corrected because the shape of the infraorbital rim or midfacial skeleton defines the overall midfacial contour.

Methods: The study included 5 cases of retruded infraorbital rim. All of the patient underwent restoration of the deficient volume using polyethylene implants between June 2005 and June 2011. The infraorbital rim was accessed through a subciliary approach, and the implants were placed in subperiosteal space. Surgical outcomes were evaluated using preoperative and postoperative computed tomography studies.

Results: Implant based augmentation was associated with a mean projection of 4.6 $\mathrm{mm}$ enhancement. No postoperative complications were noted during the 30-month follow-up period.

Conclusion: Because of the safeness, short recovery time, effectiveness, reliability, and potential application to a wide range of facial disproportion problems, this surgical technique can be applied to midfacial retrusion from a variety of etiologies, such as fracture involving infraorbital rim, congenital midfacial hypoplasia, lid malposition after blepharoplasty, and skeletal changes due to aging.
\end{abstract}

Keywords: Polyethylene / Augmentation / Orbital margin / Fracture

\section{INTRODUCTION}

The midfacial skeleton defines the facial width and cheek prominence and also forms the lateral and inferior portions of the orbit. Because hypoplasia or asymmetry of this region is prone to enophthalmos or ptosis, the contour is important for first impression and is meaningful aesthetically. Although the midface is composed of sturdy bone, it is frequently injured because of its prominent location [1].The midface is best conceptualized as having three zones, which are the infraorbital rim, the malar region, and the pyriform aperture [1]. Because the infraorbital rim and

\section{Correspondence: So Min Hwang}

Aesthetic, Plastic and Reconstructive Surgery Center, Good Moonhwa Hospital, 119

Beomil-ro, Dong-gu, Busan 48735, Korea

E-mail: nomansarea@gmail.com

Received January 13, 2016 / Revised April 19, 2016 / Accepted May 24, 2016 upper midfacial skeleton support the lower eyelids and the soft tissues of the cheek, their projection impacts lid and cheek positions [1].

Fracture of the infraorbital rim often accompanies various midfacial fractures including zygomaticomaxillary complex fracture and orbital wall fracture, which may lead to enophthalmos, scleral show, gaze limitation, asymmetric face and paresthesia. If these fractures are significant, surgical intervention is necessary [2]. In addition, the concave appearance of the infraorbital rim caused by skeletal retrusion arising from the aging process or any congenital/acquired disease requires surgical enhancement [3]. In this study, we present the use of high density polyethylene implants (Medpor, Stryker Co., Newnan, GA, USA) to reconstruct and augment the infraorbital rim. 


\section{METHODS}

The medical database was reviewed for any patient who underwent reconstruction of the infraorbital rim using polyethylene implant (Medpor) between June 2005 and June 2011, which identified 5 patients. Among the patients, surgery was indicated for an acquired condition in 1 patient, under correction from a previous operation in 2 patients, aesthetic concern in 1 patient, and recent fracture in the remaining patient. Two patients were females, and 3 patients were males. The mean age was 33.2 years (range, 15-52 years), and the mean follow-up period was 30.3 months (range, 10-69 months).

Each operation was conducted under general anesthesia with orotracheal intubation. The infraorbital rim was accessed through asubciliary incision and periosteal dissection. Once the orbital rim was exposed, the polyethylene implant (Medpor, 1.6 mm thick) was trimmed to appropriate width and length, according to the individual need for infraorbital rim augmentation (Fig. 1). The implant was slightly folded, and one side was placed on the anterior aspect of the infraorbital rim (dimensions: $1.5 \pm 0.3 \times 1.0 \pm$ $0.2 \mathrm{~cm}$ ). The other side was inserted on the orbital floor to correct enophthalmos (dimensions: $1.5 \pm 0.3 \times 0.7 \pm 0.1 \mathrm{~cm}$ ). Folding of the implant allowed for correction of enophthalmos and augmentation or reconstruction of infraorbital rim at once (Fig. 2A). Before inserting the implant, the implant convexity was decided by comparing contralateral, normal side of cheek projection vector (Table 1). Expected amount of projection was calculated by measuring

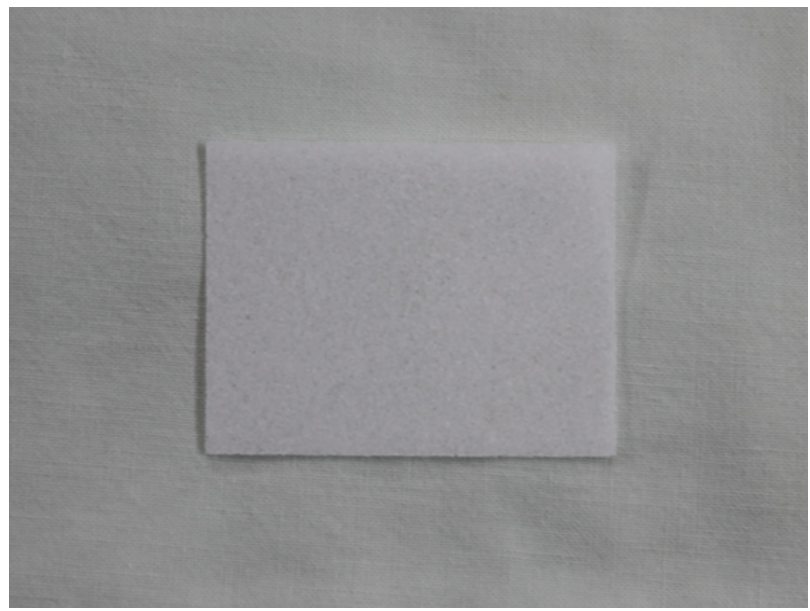

Fig. 1. The Medpor with $1.6 \mathrm{~mm}$ thickness implant was used. The length and width of implant trimmed was varied on each patient. the height of implant, which laid on the anterior aspect of infraorbital rim (Fig. 2B). Biodegradable screws (LactoSorb, Biomet Inc., Warsaw, IN, USA) or titanium screws were for rigid fixation of the implant to the infraorbital rim. The size of screws ranged from 4 to $9 \mathrm{~mm}$, depending on the size and location of the implant.

Preoperative and postoperative measurements were conducted using a vector drawn from the sagittal view of the orbital globe on CT scans. Two parallel lines were drawn as reference lines: one on the

Table 1. Distance between cheek prominence and orbital globe in the sagittal view (preoperative and postoperative analysis)

\begin{tabular}{|c|c|c|c|c|c|c|}
\hline Case & $\begin{array}{l}\text { Age } \\
\text { (yr) }\end{array}$ & Sex & Etiology & $\begin{array}{l}\text { Preoperative } \\
\text { cheek } \\
\text { projection } \\
(\mathrm{mm})^{a)}\end{array}$ & $\begin{array}{l}\text { Postoperative } \\
\text { cheek } \\
\text { projection } \\
(\mathrm{mm})^{\mathrm{a})}\end{array}$ & $\begin{array}{l}\text { Cheek } \\
\text { projection } \\
\text { in normal } \\
\text { side }(\mathrm{mm})^{\mathrm{a}}\end{array}$ \\
\hline 1 & 27 & Male & $\begin{array}{l}\text { Parry- } \\
\text { Romberg } \\
\text { syndrome }\end{array}$ & -3 & +2 & +3 \\
\hline 2 & 32 & Male & $\begin{array}{l}\text { Persistent } \\
\text { depression } \\
\text { after } \\
\text { trauma } \\
\text { following } \\
\text { previous } \\
\text { operation }\end{array}$ & -4 & -2 & 0 \\
\hline 3 & 40 & Female & $\begin{array}{l}\text { Persistent } \\
\text { depression } \\
\text { after } \\
\text { trauma } \\
\text { following } \\
\text { previous } \\
\text { operation }\end{array}$ & -2 & +3 & +3 \\
\hline
\end{tabular}

\begin{tabular}{ccccccc}
4 & 52 & Female & $\begin{array}{c}\text { For } \\
\text { aesthetics }\end{array}$ & 0 & +5 & +6 \\
\hline 5 & 15 & Male & Post-trauma & -2 & +4 & +5 \\
\hline
\end{tabular}

a) The position of the cheek prominence anterior to the orbital globe is represented in positive values; negative if posterior to the orbital globe.
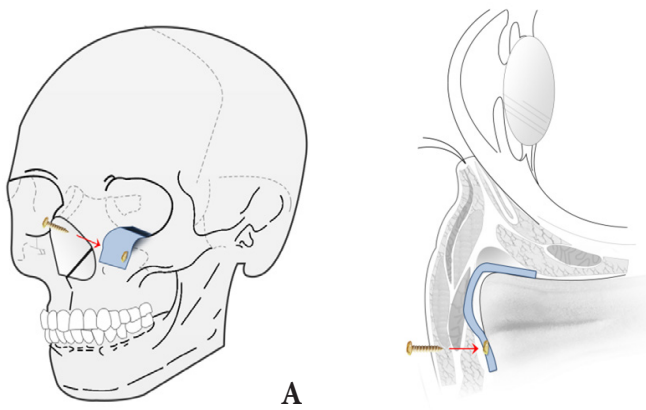

B

Fig. 2. A schema of implant contour and location. (A) Folding of the implant made both correction of enophthlmos and augmentation or reconstruction of infraorbital rim at once, by using single implant. (B) To make symmetric cheek projection, the amount of convex bending the implant was decided by comparing cheek vector of normal side. 
most anterior surface of the cornea, and the other on the soft tissue of the mid-cheek prominence. The relationship between the two was assessed and noted as a positive or negative vector (Fig. 3) [4]. The measure ments were calculated to a positive or negative value (Table 1).

\section{RESULTS}

On average, the midfacial soft tissue was approximately $2.2 \mathrm{~mm}$ posterior to the cornea. After midfacial augmentation, the cheek prominence or midfacial soft tissue volume had been increased by $4.6 \mathrm{~mm}$ on average (Table 1). Throughout the follow-up period, complications were not noted for infection, displacement of the implant, necrosis of the soft tissue, or injury of the infraorbital nerve.

\section{Case 1}

A 27-year-old man complained of progressive right facial atrophy. He reported that symptoms had started five years earlier. A careful history and examination revealed the diagnosis of Parry-Romberg syndrome. Preoperative physical examination revealed severe retraction of the right infraorbital rim (Fig. 4A, B). The patient wished for a more symmetrical appearance around the lower portion of the eyes. The patient underwent infraorbital rim augmentation with polyethylene implant, as described above. The implant was fixed with 7-mm biodegradable screws. At 10 months after surgery, the right infraorbital rim continues to maintain $5 \mathrm{~mm}$ of augmentation compared to the preoperative state (Fig. 4C, D).
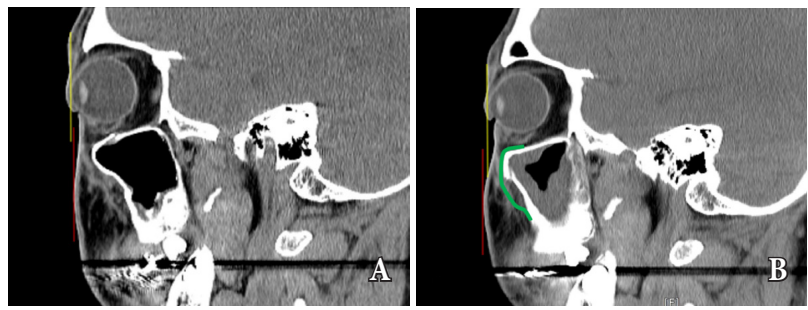

Fig. 3. A sagittal computed tomography (CT) scan shows the orbital globe to cheek prominence relationships. The yellow line indicates the most anterior surface of the cornea; the red line represents the midcheek prominence. (A) A preoperative facial CT shows the retracted cheek with a negative vector. (B) A postoperative CT scan shows that the negative vector has been reversed. Green line indicates the location of the implant.
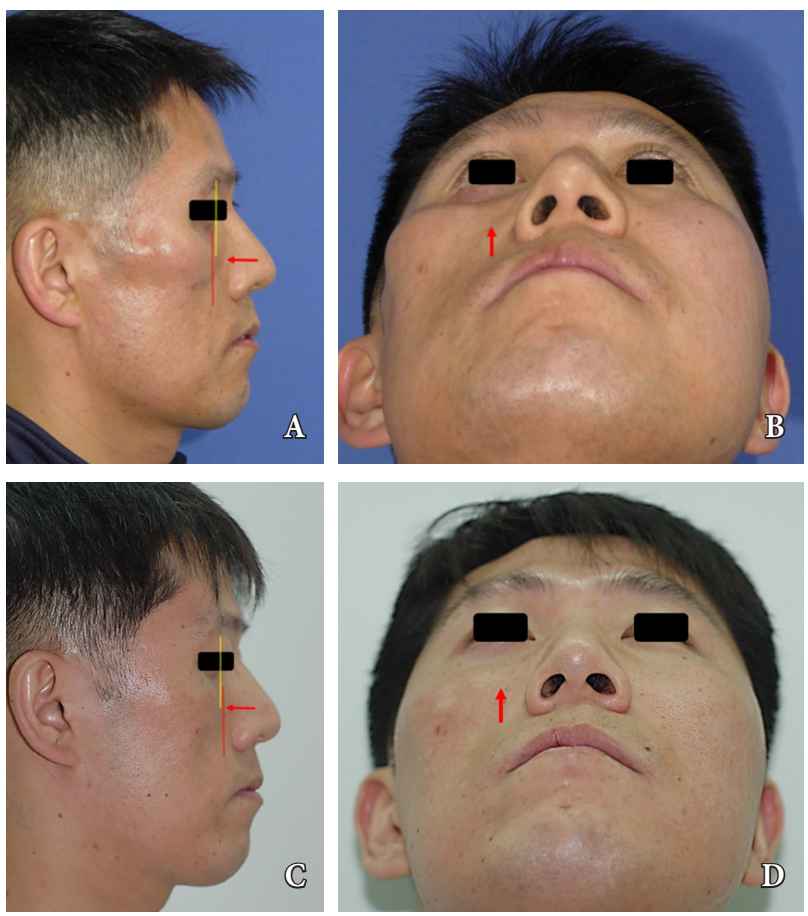

Fig. 4. Case 1. In lateral view, the yellow line indicates the most anterior surface of the cornea, and the red line represents the mid-cheek prominence. (A, B) Preoperative photograph shows depressed infraorbital rim (red arrow). (C, D) 10 months after surgery showing contour refinement (red arrow).

\section{Case 2}

A 32-year-old man with a history of zygomaticomaxillary fracture presented with numbness of the left cheek and wanted to augment the depressed infraorbital rim. Despite having undergone operative intervention after the accident last year, the patient suffered from a depression of the infraorbital rim (Fig. 5A, B). Again, a polyethylene implant was used to reconstruct the infraorbital rim (Fig. 6). At the 3-month follow up, the patient no longer experienced paresthesia, and the contour of the infraorbital rim was also improved with $2 \mathrm{~mm}$ augmentation (Fig. 5C, D).

\section{DISCUSSION}

Considering that the sagittal relationship between the orbital globe and the infraorbital rim is an important component of the facial contour, and any deformity or asymmetry of the infraorbital rim is a significant aesthetic concern. The retrusion of midfacial 

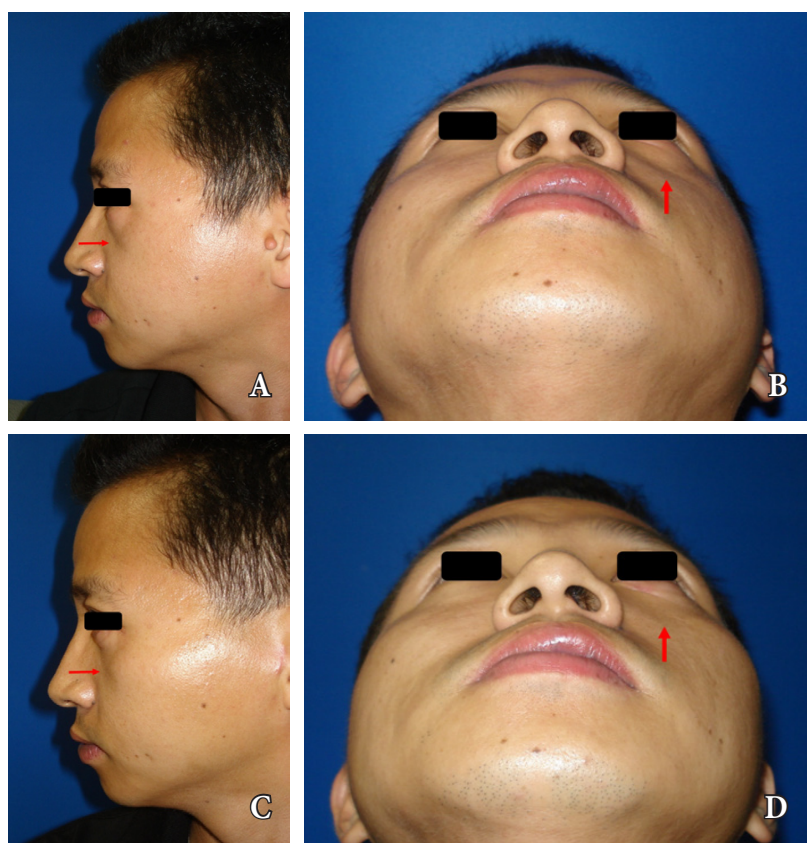

Fig. 5. Case 2. A photograph of 32-year-old male before and after the surgery. (A, B) Despite 1 year having passed since the previous surgery, an infraorbital depression remained on the left side. The small hollow (red arrow) in noted. (C, D) 3 months after the contour refinement of the infraorbital rim, showing that the volume deficit has been corrected (red arrow).

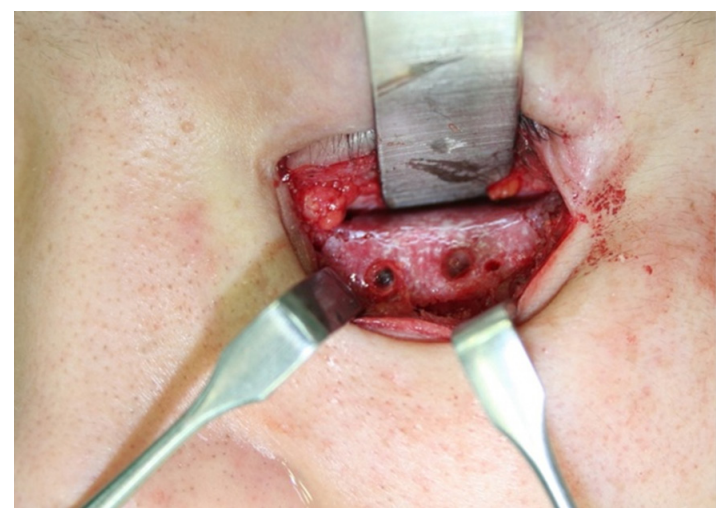

Fig. 6. An intraoperative photograph from Case 2. The microplate from the previous operation was removed. The polyethylene implant is rested on the infraorbital rim and fixated with biodegradable screws.

skeleton and the infraorbital rim can have result from an injury or a medial disease. Such depression of the infraorbital rim causes aesthetic problems like lower lid malposition after blepharoplasty [3] and also incur functional problems like cheek paresthesia [5].

Many clinical techniques have been developed in response to the functional and morphologic problems of the midfacial skeleton due to volume deficit. One method involves skeletal enhance- ment through orthognathic surgery, requiring orthodontic tooth movement or fracturing and repositioning of the facial bone [1]. However, such a complicated operation and treatment plan can be time-consuming and potentially morbid for patients without severe symptoms [6]. In contrast, relatively easier methods like free fat grafting or injection of fillers have a limited role in simulating the effect of a skeletal projection. Augmentation of the soft tissue volume results in an inflation of the soft-tissue envelope and blunting of the skeletal contour [6].

Using polyethylene implants, we were successfully able to restore, reconstruct, and augment the deficient volume of the infraorbital rim in treating the 5 cases of infraorbital rim deficiency. Compared to methods discussed above, this approach was safer, needed less recovery time, and was more reliable and effective. If the facial concavity is not severe and involves normal occlusion, an alloplastic implant alone can bring about improvements similar to that observed after Le Fort maxillary advancement. Such augmentation can also convert an aged infraorbital rim into a youthful one [6,7].

Surgical outcomes were evaluated using the sagittal relationship between the orbital globe and the mid-cheek prominence. If the cheek prominence was beyond the anterior surface of the cornea, this vector was considered as "positive", whereas the prominence posterior to the cornea was considered as "negative" [4].

The cheek soft tissue was used as a reference point in order to investigate the relationship of the overall midfacial contour (Fig. 3). For evaluating postoperative results, an exophthalmometer was not used to avoid parallax error. Instead, postoperative results were evaluated using CT images to exclude human measurement errors [8].

By using polyethylene implants, we were able to provide up to $4.6 \mathrm{~mm}$ of anterior projection of the infraorbital rim. In order to prevent globe-rim disproportion or asymmetry of the midface, it has been frequently emphasized that the infraorbital rim and the adjacent anatomy must be fully exposed to ensure the ideal placement of the implant. In most of the cases, the location of infraorbital foramen correlates with the second premolar on a vertical axis, and studies have reported that the average distance between the infraorbital foramen and the infraorbital rim was approximately $8.61 \mathrm{~mm}$ in men and $8.25 \mathrm{~mm}$ in women [9]. Therefore, 
awareness of this region may help surgeons to identify the ideal location for the implant as well as to avoid nerve injury. In this study, postoperative complications were minimized by placing the implant on the most anterior aspect of the infraorbital rim.

In conclusion, the use of a polyethylene implant was associated with satisfactory outcomes when augmenting the midfacial skeleton. The procedure is safe and effective, and the surgical technique could be applied to correct a wide variety of facial asymmetries due to fracture, any disease that distorts the contour of the face, recessed midfacial structures from aging, or to prevent or address lid malposition after blepharoplasty. Moreover, the midfacial skeleton can be made convex to promote a youthful appearance for aesthetic reasons.

\section{REFERENCES}

1. Neligan P, Rodriguez ED, Losee JE. Plastic surgery, Volume three. London; New York: Elsevier Saunders; 2013.
2. Bae SH, Kang KD, Nam SB, Bae YC, Choi SJ. Orbital floor reconstruction through endoscopic transnasal approach alone. Arch Craniofac Surg 2012;13:99-103.

3. Yaremchuk MJ, Kahn DM. Periorbital skeletal augmentation to improve blepharoplasty and midfacial results. Plast Reconstr Surg 2009;124:2151-60.

4. Yaremchuk MJ. Restoring palpebral fissure shape after previous lower blepharoplasty. Plast Reconstr Surg 2003;111:441-50.

5. Prachur K, Godhi S, Lall AB, Ram CS. Evaluation of neurosensory changes in the infraorbital nerve following zygomatic fractures. J Maxillofac Oral Surg 2012;11:394-9.

6. Yaremchuk MJ. Making concave faces convex. Aesthetic Plast Surg 2005;29:141-7.

7. Binder WJ. Facial rejuvenation and volumization using implants. Facial Plast Surg 2011;27:86-97.

8. von Wilmowsky C, Bergauer B, Nkenke E, Neukam FW, Neuhuber W, Lell M, et al. A new, highly precise measurement technology for the in vitro evaluation of the accuracy of digital imaging data. J Craniomaxillofac Surg 2015;43:1335-9.

9. Raschke R, Hazani R, Yaremchuk MJ. Identifying a safe zone for midface augmentation using anatomic landmarks for the infraorbital foramen. Aesthet Surg J 2013;33:13-8. 